\title{
Construindo a segurança alimentar? A experiência recente dos CONSADs no Brasil Meridional
}

Flávio Sacco dos Anjos* Nádia Valleda Caldas**

Resumo: O trabalho analisa a experiência recente dos Consórcios de Desenvolvimento Local e Segurança Alimentar (CONSADs) no Sul do Brasil a partir de estudo realizado pela Universidade Federal de Pelotas em conjunto com a FAO e Ministério do Desenvolvimento Social. A pesquisa examinou 137 projetos de desenvolvimento visando avaliar o grau de identidade com os objetivos de combate à fome e à insegurança alimentar. O estudo mostra que o CONSAD pode ser uma via capaz de induzir à proposição de instrumentos que atendam a esses imperativos. Entrementes, há importantes obstáculos a suplantar, entre os quais, o próprio desenho institucional e o recorte geográfico do CONSAD, assim como o "viés agrarista" dos projetos de desenvolvimento, o excessivo protagonismo dos poderes públicos e as incompreensões em torno ao conceito de segurança alimentar por parte dos atores sociais envolvidos.

Palavras-chave: segurança alimentar; desenvolvimento rural, políticas públicas.

Classificação JEL: R58; R13; Z13.

* Doutorem SociologiaeDesenvolvimento Rural, Pesquisador doCUPeProfessor do ProgramadePós-GraduaçãoemSistemasdeProdução AgrícolaFamiliardaUniversidadedePelotas. flaviosa@ufpel.edu.br

** Cientista Social e Mestranda do Programa de Pós-Graduação em Sistemas de Produção Agrícola Familiar da Universidade Federal de Pelotas. nvcaldas@ufpel.edu.br 
Abstract: This work analyzes the recent experience of the "Consortium of Local Development and Alimentary Security" (CONSADs) in the southern Brazil based in a study carried out by Federal University of Pelotas together FAO and Brazilian Social Development Ministry. The research examined 137 development projects aiming to evaluate the similarity degree of their objectives with those of the hunger and alimentary insecurity combat. The study shows that the CONSAD can represent a way capable to induce the proposition of instruments to attend these imperatives. Meantime, there are important obstacles to supplant, such as the institutional design and the CONSAD geographic delimitation, as well as the "agrarian bias" of the development projects, the excessive protagonism of public agents and the misunderstandings about to the concept of alimentary security from the point of view of the involved social actors.

Key words: alimentary security; rural development; public policies.

JEL Classification: R58; R13; Z13.

\section{Introdução}

Há exatos 40 surgia um dos mais importantes estudos etnográficos brasileiros: "Os parceiros do Rio Bonito". Nesta obra seminal sobre o tema da segurança alimentar, Antonio Cândido, propõe uma "sociologia dos meios de subsistência” de forma a contemplar a complexidade dos fenômenos envolvidos. Em resumidas contas, é destacado o fato das necessidades alimentares terem um duplo caráter: natural e social, mais além de representarem simples impulsos orgânicos (CÂNDIDO, 1987, p.23). O ato de alimentar-se, como resumiu este autor, torna-se o centro de um dos mais vastos complexos culturais, "abrangendo atos, normas, simbolos, representações"

Desconhecer ou minimizar a dimensão destes atributos torna inconsistente toda e qualquer discussão relativa ao tema da segurança alimentar, tanto do ponto de vista estritamente acadêmico quanto na perspectiva das políticas públicas. No caso brasileiro, como é sabido,

${ }^{1}$ Op.cit., p.29. 
há uma importante renovação no debate na medida em que o combate à fome e à insegurança alimentar converte-se em bandeira política e objeto do processo de intervenção estatal.

É justamente no contexto desse processo que o governo federal promove a implantação dos "Consórcios de Segurança Alimentar e Desenvolvimento Local” (doravante referidos como CONSADs) em vários pontos do território nacional. Trata-se de uma nova institucionalidade que congrega em torno de si agentes públicos e privados, orientados à elaboração de programas de desenvolvimento local, combate à fome e à insegurança alimentar.

O presente estudo é resultante de uma pesquisa mais ampla, conduzida sob os auspícios de um acordo de cooperação técnica firmado entre a FAO e o governo brasileiro, inicialmente representado pelo Ministério Extraordinário de Segurança Alimentar e Combate à Fome (MESA), atualmente Ministério do Desenvolvimento Social e Combate à Fome.

A investigação, sinteticamente denominada de TCP FAO/BRA/2905, desencadeou-se junto aos nove (9) recém-instalados CONSADs das regiões Sul, Sudeste e Centro-Oeste, respectivamente realizada por pesquisadores vinculados às Universidades Federais de Pelotas, Lavras e Uberlândia. No marco dessa pesquisa, constavam dois objetivos fundamentais:

1) A montagem de uma metodologia de referência que identificasse, caracterizasse e classificasse, em ordem de prioridade para o Programa Fome Zero, projetos intermunicipais de desenvolvimento (PIDs), no contexto dos recém instalados CONSADs;

2) A testagem da metodologia de avaliação, colocando-a em prática nas áreas de atuação correspondentes aos nove CONSADs, com vistas ao esforço de replicação junto às regiões do Norte e Nordeste brasileiro. Na região Sul do Brasil o estudo envolveu os CONSADs de Missões, Campos de Lages e Pitanga, respectivamente instalados nos estados do Rio Grande do Sul, Santa Catarina e Paraná.

Além desta introdução, reunimos, na secção subseqüente, uma breve resenha da metodologia utilizada, assim como uma rápida descrição das características fundamentais dos territórios aqui enfocados. A terceira secção é dedicada à apresentação dos resultados do trabalho, com ênfase na discussão sobre a natureza dos projetos locais e projetos intermunicipais de desenvolvimento identificados (doravante chama- 
dos de PIDs) neste estudo. Trata-se, como oportunamente veremos, de examinar seu alcance e objetivos à luz da metodologia proposta no marco do TCP FAO/BRA/2905.

A quarta secção apresenta algumas das dificuldades a serem transpostas na consolidação dos CONSADs enquanto espaço privilegiado de discussão sobre a eficácia dos instrumentos de combate à fome e à insegurança alimentar. Apresentaremos alguns dos dilemas com que nos deparamos no contato com a realidade concreta e com os atores sociais envolvidos. A quinta e última secção reúne as considerações finais dessa pesquisa.

\section{A metodologia e o universo empírico da pesquisa}

\section{Metodologia e instrumentos de pesquisa}

No Sul do Brasil o trabalho desenvolveu-se entre janeiro e agosto de 2004 envolvendo fundamentalmente o uso de metodologias qualitativas, tais como entrevistas, observação participante em reuniões e eventos locais, regionais, bem como o levantamento de informações que permitissem conhecer a dinâmica dos processos sócio-políticos no âmbito dos CONSADs. Inclui-se aí a análise de documentos disponibilizados pelas prefeituras municipais, extensionistas rurais, instituições religiosas, organizações não-governamentais e agências de desenvolvimento (públicas e privadas). Não menos importante foi o cotejo com os dados secundários, sobretudo com as fontes censitárias.

Uma equipe de 15 pesquisadores realizou cerca de 270 entrevistas que tiveram como interlocutores um conjunto extremamente diversificado de atores sociais da esfera pública e privada, vinculados a organizações civis e a processos de intervenção cujo enfoque varia segundo a natureza dos objetivos perseguidos e as circunstâncias envolvidas. Esse quadro exigiu uma dedicação ainda maior no controle das informações e na adequação dos instrumentos de avaliação dos projetos, os quais foram agrupados em três grandes categorias:

1) projetos intermunicipais de desenvolvimento consolidados: iniciativas orientadas ao combate à fome, à insegurança alimentar e ao desenvolvimento, incidindo ao menos sobre dois municípios do CON- 
SAD. Trata-se de projetos que já se encontravam em funcionamento por ocasião do levantamento.

2) projetos intermunicipais em fase de estruturação: projetos que perseguem os mesmos objetivos mas que não haviam sido implantados por ocasião da pesquisa. Em sua grande maioria constam do "cardápio de projetos” elaborados ou em fase de elaboração pelo próprio CONSAD, requeridos pelo Governo Federal.

3) projetos locais de desenvolvimento: consistem em projetos que incidem estritamente no plano local, ainda que comprometidos com os mesmos princípios e objetivos dos projetos anteriores.

Na metodologia de avaliação construída pelo TCP FAO/BRA/2905 foram propostos sete (7) critérios de avaliação dos projetos.

a) o pacto político: avaliou-se a natureza das alianças construídas em torno ao projeto, do ponto de vista das relações e dos papéis atribuídos aos atores sociais envolvidos, públicos e/ou privados; b) a abrangência do projeto: avaliou-se a incidência em termos do número de municípios envolvidos; c) os impactos sobre a segurança alimentar: avaliou-se o número de pessoas efetivamente atendidas em relação à população de indigentes existente nos municípios em que o mesmo projeto incide ou se propõe a incidir; d) os impactos sobre pessoas em risco de insegurança alimentar: avaliou-se o número de pessoas efetivamente atendidas em relação ao total de pessoas pobres nos municípios em que o projeto incide; e) viabilidade institucional: compreende a análise sobre as perspectivas futuras do projeto; f) sustentabilidade financeira: como o próprio nome indica, tal quesito compreende a análise sobre a solidez dos mecanismos de sustentação financeira do projeto; g) riscos do projeto: o exame recai sobre a existência de possíveis riscos do ponto de vista ambiental ou de qualquer outra natureza.

Para cada um dos quesitos foi atribuído um valor correspondente a uma escala que vai do 0 (zero) ao 5. Conseqüentemente, o valor máximo que um projeto poderia receber seria 35 pontos no total. À exceção dos itens b, c, d, todos os demais critérios apresentam um considerável grau de subjetividade na avaliação. Outrossim, como ficou demonstrado, o cruzamento de informações e a realização de entrevistas com diversos atores sociais permitiu reafirmar a confiabilidade dos dados que embasaram os conceitos atribuídos. 
Há outro aspecto que deve ser esclarecido. O foco da pesquisa recaiu essencialmente sobre os projetos intermunicipais de desenvolvimento. Entretanto, julgou-se oportuno o levantamento e análise das experiências locais de desenvolvimento na medida em que muitas delas mostravam-se extremamente meritórias e passíveis de serem replicadas em outras realidades ou ampliadas a outros municípios, convertendose, em efeito, num projeto intermunicipal. Todavia, para manter a coerência e equilíbrio dos critérios de avaliação, optou-se por atribuir nota zero (0) no quesito "abrangência do projeto".

No caso dos PIDs em fase de estruturação, a análise baseou-se em cima de projeções sobre a natureza e incidência do projeto que foi concebido no âmbito do CONSAD, em que pese o fato de não haver sido implementado por ocasião da pesquisa.

\section{O Universo empírico: os CONSADs de Missões, Campos de Lages e Pitanga}

É impossível retratar, ainda que resumidamente, a diversidade econômica, social, política e ambiental que abrigam os territórios correspondentes aos CONSADs na região Sul do Brasil. O elemento que os unifica reside, indubitavelmente, na existência de grandes contrastes em termos das condições sociais de existência das populações e do distinto grau de desenvolvimento em que as localidades encontram-se, quando confrontadas entre si e no âmbito dos próprios CONSADs investigados.

Os dados da Tabela 1 mostram que o CONSAD Missões reúne o maior número de municípios (25) dentre todos os CONSADs estudados da região Sul do Brasil. A mesma fonte indica que os três CONSADs sulistas representam um universo de 741.375 pessoas, considerando que desse total, 36,1\% corresponde a Missões, 38,2\% a Campos de Lages e $25,7 \%$ a Pitanga. Essas mesmas proporções não se verificam, entretanto, no que afeta à distribuição dos pobres e indigentes. Pitanga concentra nada menos que $40,1 \%$ do total de pobres existentes nos três CONSADs, enquanto Campos de Lages e Missões ficam com respectivamente $28,6 \%$ e $31,3 \%$ desse contingente. Com relação aos indigentes, a participação de Pitanga é ainda maior $(42,3 \%)$, enquanto no CONSAD Campos de Lages e Missões ela é de respectivamente 25,2\% e 32,5\%. 
Apesar destas diferenças, que aparecem refletidas nas grandes discrepâncias em termos dos índices de desenvolvimento humano e econômico, os três CONSADs apresentam como elemento recorrente o fato de serem regiões invariavelmente acometidas pelo êxodo rural, além de outros fenômenos demográficos igualmente importantes, como é o caso da masculinização e envelhecimento, detectadas em outros estudos debruçados sobre a mesma realidade (CAMARANO e ABRAMOVAY, 1997; SACCO DOS ANJOS, 2003; SACCO DOS ANJOS e CALDAS, 2003).

Tabela 1. Número de municípios, habitantes e área em $\mathrm{km}^{2}$ dos CONSADs do Sul do Brasil.

\begin{tabular}{lrrrr}
\hline \multicolumn{1}{c}{ Variável } & \multicolumn{1}{c}{ RS } & \multicolumn{1}{c}{ SC } & \multicolumn{1}{c}{ PR } & \multicolumn{1}{c}{ Total } \\
\hline Número de municípios & 25 & 18 & 18 & 61 \\
Número de habitantes & 267.536 & 283.005 & 190.834 & 741.375 \\
Número de Pobres & 85.694 & 78.315 & 109.513 & 273.522 \\
Indigentes & 38.337 & 29.814 & 49.952 & 118.103 \\
\hline Área em Km & $12.412,452$ & $15.726,013$ & $12.403,691$ & $40.542,156$ \\
\hline
\end{tabular}

Fonte: Elaborado a partir do Censo Demográfico (IBGE, 2000).

No âmbito de cada CONSAD as atividades agropecuárias representam o principal esteio da economia regional, com ênfase no peso das commodities (soja e trigo) no caso das Missões. Nos Campos de Lages figuram em destaque a pecuária de corte, milho e silvicultura através de projetos de reflorestamento destinados à produção de madeira e celulose. No caso de Pitanga a importância recai sobre as culturas do milho, soja, aveia, feijão e erva-mate, assim como em projetos agroflorestais. O escasso grau de industrialização regional, a concentração das atividades econômicas e dos fatores de produção explicam, em parte, a baixa capacidade de retenção da população, particularmente no que afeta as pequenas localidades que conformam estes três CONSADs.

Esclarecidos os objetivos e a metodologia da pesquisa, assim como os traços essenciais dos territórios investigados, analisemos os projetos efetivamente diagnosticados, suas características fundamentais e a avaliação empreendida. 


\section{Resultados do trabalho}

\section{Análise sobre os aspectos gerais dos projetos de desenvolvimento diagnosticados}

Identificar projetos intermunicipais de desenvolvimento, caracterizá-los segundo seus grandes objetivos e classificá-los, com ênfase no combate à fome e à insegurança alimentar, representavam, como dissemos, as três grandes metas do TCP FAO/BRA 2905. Tratava-se, além disso, de oferecer uma carteira de projetos que oportunamente poderiam ser apoiados pelo próprio CONSAD, mediante aporte de recursos do poder público municipal, estadual, federal ou mesmo de organismos internacionais, segundo os critérios de avaliação e classificação adotados no marco metodológico dessa pesquisa.

A importância de conhecê-los em profundidade e de classificá-los, segundo a convergência em relação ao esforço de combater a fome, a desnutrição e a insegurança alimentar não pode estar desconectada da luta por indicar novos caminhos a serem trilhados no campo do desenvolvimento e da inclusão social.

Melhor ainda se o ponto de partida levasse em conta o que estivesse acontecendo na própria região como representativo do que poder-se-ia chamar de boas práticas de intervenção junto à realidade social. Ao fim e ao cabo, partiu-se da premissa de que são "os projetos que moldam os territórios” (KAYSER et al, 1994). Do mesmo modo, caberia aprofundar no exame de realidades que discrepavam entre si em relação à densidade do seu respectivo capital social nos termos definidos na literatura (COLEMAN, 1990; PUTNAM, 1996), entre os CONSADs estudados e inclusive entre os próprios municípios que dele fazem parte.

Coube ao $\mathrm{IBAM}^{2}$ propor um recorte espacial que definisse o número de municípios integrantes de cada CONSAD, com base no que consideram como princípio da "identidade microrregional". Em muitos dos CONSADs dito recorte resultou um desenho territorial ${ }^{3}$ que se aproxima do conceito de microrregião homogênea adotada pelo IBGE, ao passo que em outras

\footnotetext{
${ }^{2}$ Instituto Brasileiro de Administração Municipal.

${ }^{3}$ Ver a propósito Franca (2003): CONSAD - Formação de Consórcios de Segurança Alimentar e Desenvolvimento Local.
} 
situações optou-se por outro arranjo que incluiu localidades integrantes de até mesmo três microrregiões, como é o caso do CONSAD Missões.

Como mostra a Tabela 2, nos três CONSADs sulistas foram identificados, tal como aludimos anteriormente, 137 projetos de desenvolvimento. Destes, 36 são projetos intermunicipais de consolidados, 13 encontravam-se em fase de estruturação e 88 são projetos locais de desenvolvimento. À exceção do CONSAD Pitanga (PR), que à época do levantamento não dispunha de um plano de ação ou de um rol de projetos sistematizados, foram incluídas 13 iniciativas no processo de avaliação do que se denominou como PIDs "em fase de estruturação", seis deles no CONSAD Missões e sete no CONSAD Campos de Lages.

Em função do espaço que aqui dispomos centraremos a discussão em torno dos projetos locais e dos projetos intermunicipais de desenvolvimento por serem as experiências mais importantes para os objetivos que persegue esse artigo.

Tabela 2. Projetos de desenvolvimento consolidados, em fase de estruturação e locais nos CONSADs de Missões (RS), Campos de Lages (SC) e Pitanga (PR).

\begin{tabular}{lcccc}
\hline \multicolumn{1}{r}{ Tipo de Projeto } & \multicolumn{4}{c}{ Número de Projetos } \\
& RS & SC & PR & Total (SUL) \\
\hline PIDs consolidados & 11 & 09 & 16 & 36 \\
PIDs em estruturação & 06 & 07 & - & 13 \\
Projetos Locais & 28 & 11 & 49 & 88 \\
Total & 45 & 27 & 65 & 137 \\
\hline
\end{tabular}

Fonte: Pesquisa de Campo (2004).

Existe, como mostra a Tabela 3, uma grande discrepância entre os projetos analisados segundo o número de famílias beneficiadas nas duas modalidades aqui enfocadas. Entre os PIDs consolidados, os que apresentam o maior alcance total (25.058 famílias) estão no CONSAD de Pitanga, assim como no número médio de famílias beneficiadas por projeto $(1.566,1)$, seguidos respectivamente pelo CONSAD Missões (7.395 famílias no total e 672,3 famílias/projeto) e Campos de Lages (3.899 famílias no total e 433,2 famílias/projeto).

Com relação aos projetos locais de desenvolvimento, é no CONSAD Pitanga onde existe um maior alcance do ponto de vista de ambos 
quesitos, seguido de Missões e Campos de Lages. Através dos dados da Tabela 3 é possível estimar também um número médio de famílias atendidas por projeto, correspondente a 335,0 no Paraná, 151,6 no Rio Grande do Sul e 116,4 em Santa Catarina.

Se comparados com os PIDs, parece óbvio que estas iniciativas locais atendem a um número consideravelmente pequeno de pessoas. Outrossim, a priori não pode ser minimizada sua relevância, posto que, como mostrou a realidade, algumas delas são extremamente meritórias em termos dos objetivos que perseguem, considerando ainda o fato de que invariavelmente funcionam a partir da contribuição e do trabalho voluntário das próprias comunidades.

Tabela 3. Descrição dos projetos de desenvolvimento segundo o número total e número médio de famílias beneficiadas por projeto.

\begin{tabular}{|c|c|c|c|c|c|c|c|c|}
\hline \multirow{3}{*}{ Tipo de Projeto } & \multicolumn{8}{|c|}{ Número de famílias beneficiadas } \\
\hline & \multicolumn{2}{|r|}{ RS } & \multicolumn{2}{|c|}{ SC } & \multicolumn{2}{|c|}{ PR } & \multicolumn{2}{|c|}{ Total (SUL) } \\
\hline & Total & No Médio & Total & $\mathrm{N}^{0}$ Médio & Total & $\mathrm{N}^{0}$ Médio & Total & $\mathrm{N}^{0}$ Médio \\
\hline PIDs consolidados & 7.395 & 672,3 & 3.899 & 433,2 & 25.058 & $1.566,1$ & 36.352 & $1.009,7$ \\
\hline Projetos Locais & 4.246 & 151,6 & 1.281 & 116,4 & 16.417 & 335,0 & 21.944 & 249,4 \\
\hline
\end{tabular}

Fonte: Pesquisa de Campo (2004).

Nesse sentido, os dados da Tabela 4 evidenciam, entre outras coisas, o baixo custo médio dos projetos locais de desenvolvimento, especialmente no caso catarinense onde ascendem, em média, a apenas R \$ 20.400,00 por projeto. No CONSAD Missões (RS) o custo médio é de $\mathrm{R} \$ 49.600,00$, ao passo que no CONSAD Pitanga ele ascende a $\mathrm{R} \$$ 72.800,00. No que afeta aos PIDs consolidados a situação é praticamente idêntica no caso catarinense e gaúcho, ao passo que no Paraná o custo médio estimado desta modalidade de projeto é de $\mathrm{R} \$ 669.800,00$.

Os dados da Tabela 5 complementam a informação sobre o custo dos projetos analisados. Entre os projetos que apresentam o melhor desempenho, em termos médios, são os projetos locais do CONSAD Campos de Lages (SC), com um custo médio de R\$174,9 por família beneficiada. Seguem-lhe, em ordem crescente de valor, os projetos locais do CONSAD Pitanga (PR), com um custo médio estimado em R\$ 217,2/família beneficiada. 
Por outra parte, os dados relativos aos PIDs consolidados dos três territórios examinados aproximam-se bastante do ponto de vista deste critério de análise.

Tabela 4. Custo total e médio dos projetos de desenvolvimento nos três CONSADs da região Sul do Brasil.

\begin{tabular}{lrrrrrr}
\hline \multirow{2}{*}{ Tipo de Projeto } & \multicolumn{2}{c}{ RS Custo dos projetos em mil Reais (R\$) } \\
& \multicolumn{1}{c}{ Total } & Médio & \multicolumn{1}{c}{ Total } & MC & \multicolumn{2}{c}{ PR } \\
& PIDs consolidados & \multicolumn{1}{c}{ Total } & Médio \\
\hline Projetos Locais & $2.125,2$ & 193,2 & $1.730,2$ & 192,3 & $10.717,4$ & 669,8 \\
\hline
\end{tabular}

Fonte: Pesquisa de Campo (2004).

Tabela 5. Custo médio dos projetos de desenvolvimento nos três CONSADs da região Sul do Brasil por família beneficiada.

\begin{tabular}{lcrr}
\hline \multirow{2}{*}{ Tipo de Projeto } & \multicolumn{2}{c}{$\begin{array}{c}\text { Custo médio dos projetos em mil Reais (R\$) por } \\
\text { família beneficiada }\end{array}$} \\
& RS & SC & PR \\
\hline PIDs consolidados & 287,4 & 443,7 & 427,7 \\
Projetos Locais & 327,1 & 174,9 & 217,2 \\
\hline
\end{tabular}

Fonte: Pesquisa de Campo (2004).

Em se tratando de oferecer aos membros do CONSAD uma carteira de projetos passíveis de serem financeiramente apoiados e estendidos a outras realidades, o dado relativo ao respectivo custo por família tornase sumamente importante como mecanismo de escolha sobre qual a melhor iniciativa a ser fomentada num contexto de restrição orçamentária e de escassez de recursos.

Qual o melhor projeto? Contornando dificuldades...

Percorrer 61 municipalidades, identificar, caracterizar e classificar projetos de desenvolvimento, segundo sua natureza e objetivos, exigiu uma energia considerável para gerir toda a diversidade de informações produzidas. Entrementes, mais difícil ainda resultou o esforço por adaptar os instrumentos de avaliação quanto ao mérito e adequação 
das propostas às metas correspondentes ao combate à fome e à insegurança alimentar.

Resumidamente é possível dizer que a atenção estava posta em algumas questões gerais ou eixos temáticos sobre aspectos tais como: Qual a idéia-guia que orienta o projeto? Qual sua abrangência física em termos dos municípios beneficiados? Qual é a instituição líder? Quais as categorias sociais privilegiadas? Qual a natureza das ações efetivamente implementadas no âmbito da segurança alimentar?

Seria impossível apresentar, no espaço que aqui dispomos, as características fundamentais dos 88 projetos locais de desenvolvimento. Outrossim, antes de entrar propriamente na discussão sobre o processo de avaliação, torna-se crucial discorrer sobre alguns dos interrogantes formulados no parágrafo anterior. Na Tabela 6 eles aparecem agrupados segundo o enfoque respectivo ou idéia-guia dominante. É mister registrar que, em muitos casos, ditos projetos perseguem múltiplos objetivos ou finalidades bastante difusas. Nesse caso, optou-se por eleger a ação prioritária para fins de enquadramento dentre as categorias propostas.

Os dados mostram que é indiscutivelmente a organização de produtores, de cadeias produtivas, feiras e outras ações voltadas à comercialização de produtos agropecuários a opção preponderante, ou o que aqui denominamos como "idéia-guia dominante", concentrando nada menos que $42,0 \%$ dos projetos locais de desenvolvimento. Seguemlhe, em ordem de importância as ações em prol da geração de renda $(17,0 \%)$, construção de hortas, hortos medicinais e agroindústrias comunitárias (13,6\%) e ações sócio-educativas (11,4\%).

A informação reunida na Tabela 6 é complementada com os dados apresentados na Tabela 7, a qual indica o ator social, grupo ou categoria sócio-política identificada como objeto destas ações de desenvolvimento local. Aparece indiscutivelmente destacado o grupo que inclui agricultores familiares, pescadores e assentados de reforma agrária, concentrando nada menos que 48,9\% dos projetos locais de desenvolvimento na condição de protagonistas destas ações, seguidos das famílias em situação de pobreza e/ou insegurança alimentar (22,7\%). A última linha da Tabela 7 reúne situações onde não está claramente definido qual o público-alvo do projeto local; muitas delas referem-se 
a categorias sociais muito distintas entre si ou até mesmo discrepantes em termos de suas características essenciais ${ }^{4}$.

Tabela 6. Distribuição dos projetos locais de desenvolvimento segundo a idéia-guia dominante.

\begin{tabular}{lrrrrrr}
\hline & \multicolumn{5}{c}{ Número de projetos locais de } \\
& \multicolumn{5}{c}{ desenvolvimento } \\
& RS & SC & PR & Total & \% \\
\hline Crédito Rotativo, Microfinanças, Microcrédito & 01 & 01 & 01 & 03 & 3,4 \\
Hortas, hortos medicinais e agroindústrias comunitárias & 05 & 01 & 06 & 12 & 13,6 \\
Geração de Renda (artesanato, turismo etc.) & 05 & 03 & 07 & 15 & 17,0 \\
Ações assistenciais (dirigidas a jovens, mulheres, idosos) & 02 & 01 & 05 & 08 & 9,1 \\
Organização de produtores, cadeias, feiras e comercialização & 10 & 04 & 23 & 37 & 42,0 \\
Ações sócio-educativas & 05 & - & 05 & 10 & 11,4 \\
Apoio a grupos étnicos (indígenas, quilombolas) & - & - & 01 & 01 & 1,2 \\
Outra orientação & - & 01 & 01 & 02 & 2,3 \\
Total & 28 & 11 & 49 & 88 & 100,0 \\
\hline
\end{tabular}

Fonte: Pesquisa de Campo (2004).

O processo de avaliação proposto identificou os melhores projetos classificados dentre os 88 analisados no âmbito dos três CONSADs do Brasil meridional. Apenas dez $(11,4 \%)$ deles alcançaram uma pontuação considerada alta, incluindo-se nesta condição as iniciativas que atingiram 25 ou mais pontos dentre os 30 possíveis no contexto de projetos locais de desenvolvimento. Muitas ações, quando incidem sobre os objetivos de segurança alimentar e inclusão social, são alvo de uma cultura política, ainda arraigada no país, no qual ao ingressar uma nova administração, projetos e iniciativas, até então existentes, são literalmente abandonadas.

Em outros casos o projeto não se sustenta financeiramente ou apresenta um viés estritamente assistencialista em sua dinâmica de funcionamento. Ainda assim, é fundamental registrar a importância de algumas iniciativas que devem ser levadas em conta no contexto da formulação de novos mecanismos em relação ao tema da segurança alimentar e nutricional.

${ }^{4}$ Referimo-nos, para efeitos de ilustração, a alguns projetos que visam genericamente beneficiar agricultores vinculados à alguma cadeia produtiva, sejam eles agricultores familiares ou patronais. 
Tabela 7. Distribuição dos projetos locais de desenvolvimento segundo o ator social, grupo ou categoria sócio-política objeto das ações desenvolvimento local.

\begin{tabular}{lrrrrrr}
\hline \multirow{1}{*}{\multicolumn{1}{c}{ Ator social ou categoria sócio-política }} & \multicolumn{5}{c}{ Número de projetos locais de } \\
& RS & SC & PR & Total & \% \\
\hline Agricultor familiar, pescador, assentado de reforma agrária & 15 & 04 & 24 & 43 & 48,9 \\
Famílias em situação de pobreza ou insegurança alimentar & 03 & 03 & 14 & 20 & 22,7 \\
Mulheres rurais & 03 & - & 14 & 03 & 3,4 \\
Estudantes, crianças e/ou adolescentes & 03 & - & - & 09 & 10,2 \\
Outros e/ou indefinido & 01 & 04 & 08 & 13 & 14,8 \\
Total & 28 & 11 & 49 & 88 & 100,0 \\
\hline
\end{tabular}

Fonte: Pesquisa de Campo (2004).

Examinemos agora os PIDs propriamente ditos.

Os projetos intermunicipais de desenvolvimento: construindo a segurança alimentar?

Os 36 projetos intermunicipais de desenvolvimento identificados nos três CONSADs da região Sul do Brasil foram classificados conforme a idéia-guia dominante, tal como mostram os dados da Tabela 8. Alguns aspectos podem ser, de imediato, identificados.

Em primeiro lugar, vemos que não há uma única ação que contemple grupos étnicos específicos (indígenas e/ou quilombolas). Para ilustrar essa questão basta dizer que na região missioneira gaúcha há inúmeros aldeamentos indígenas, onde o principal apelo turístico que se busca potencializar recai justamente nas ruínas das reduções jesuíticas.

Outrossim, os traços histórico-culturais que conformam a própria identidade gaúcha são fortemente tributários da contribuição da cultura guaranítica. Paradoxalmente, na prospecção realizada no marco dessa pesquisa, não foram detectados projetos de desenvolvimento que conectem os aldeamentos dentro de uma lógica emancipatória, de maneira a fugir da armadilha do assistencialismo vulgar.

Do mesmo modo, é marcante a hegemonia de projetos ancorados na questão da organização de produtores, apoio a cadeias agroindustriais, feiras e outras iniciativas de fortalecimento ao processo de comercialização. Esta classe de iniciativas concentra quase $42 \%$ dos projetos intermunicipais de desenvolvimento no contexto dos CONSADs sulistas. 
Seguem-lhe, em ordem de importância $(13,9 \%)$, os projetos que têm por foco as ações assistenciais dirigidas a grupos específicos (jovens, mulheres, idosos).

Tabela 8. Distribuição dos projetos intermunicipais de desenvolvimento segundo a idéia-guia dominante.

\begin{tabular}{lccccr}
\hline & \multicolumn{5}{c}{ Número de projetos locais de } \\
\multicolumn{1}{c}{ Idéia-guia dominante } & RS & SC & PR & Total & \multicolumn{1}{c}{$\%$} \\
\hline Crédito Rotativo, Microfinanças, Microcrédito & - & 02 & 01 & 03 & 8,3 \\
Hortas, hortos medicinais e agroindústrias comunitárias & 03 & - & - & 03 & 8,3 \\
Geração de Renda (artesanato, turismo etc.) & - & 02 & 01 & 03 & 8,3 \\
Ações assistenciais (dirigidas a jovens, mulheres, idosos) & - & 03 & 02 & 05 & 13,9 \\
Organiz. de produtores, cadeias, feiras e comercialização & 06 & 02 & 07 & 15 & 41,7 \\
Ações sócio-educativas & - & - & 02 & 02 & 5,5 \\
Recuperação ou preservação ambiental & 01 & - & 01 & 02 & 5,5 \\
Outra orientação & 01 & - & 02 & 03 & 8,3 \\
Total & 11 & 09 & 16 & 36 & 100,0 \\
\hline
\end{tabular}

Fonte: Pesquisa de Campo (2004).

Por outro lado, os dados da Tabela 9 dão conta do absoluto domínio da agricultura familiar enquanto ator social privilegiado, concentrando quase $53 \%$ dos projetos intermunicipais de desenvolvimento nos CONSADs do Brasil meridional. Em segundo lugar, estão os projetos que elegeram como público-alvo preferencial das ações as famílias em situação de pobreza e/ou insegurança alimentar.

Através dos dados da Tabela 10 é possível visualizar a avaliação geral dos projetos intermunicipais de desenvolvimento nos três CONSADs estudados na região sul do Brasil. A Coluna A corresponde aos projetos pior avaliados, havendo recebido até 20 pontos dentre os 35 possíveis. Na coluna B estão os que receberam uma avaliação intermediária (entre 21 e 25 pontos), ao passo que na Coluna $C$ estão os projetos que conquistaram acima de 25 pontos.

Os dados indicam que dos 36 projetos intermunicipais identificados e analisados, 15 deles ( $42 \%$ ) receberam uma avaliação bastante satisfatória, ao passo que 13 (36\%) ficaram no grupo intermediário, enquanto oito $(22 \%)$ alcançaram até 20 pontos dos 35 possíveis. 
Tabela 9. Distribuição dos projetos intermunicipais de desenvolvimento segundo o ator social, grupo ou categoria sócio-política objeto das ações desenvolvimento local.

\begin{tabular}{lccccc}
\hline \multirow{1}{*}{\multicolumn{1}{c}{ Ator social ou categoria sócio-política }} & \multicolumn{5}{c}{ Número de projetos intermunicipais } \\
& RS & SC & PR & Total & \% \\
\hline Agricultor familiar, pescador, assentado de reforma agrária & 06 & 03 & 10 & 19 & 52,8 \\
Famílias em situação de pobreza ou insegurança alimentar & 03 & 05 & 01 & 09 & 25,0 \\
Mulheres rurais & 01 & - & - & 01 & 2,8 \\
Estudantes, crianças e/ou adolescentes & - & - & 01 & 01 & 2,8 \\
Outros e/ou indefinido & 01 & 01 & 04 & 06 & 16,7 \\
Total & 11 & 09 & 16 & 36 & 100,0 \\
\hline
\end{tabular}

Fonte: Pesquisa de Campo (2004).

Tabela 10. Distribuição dos projetos intermunicipais de desenvolvimento nos três CONSADs sulistas segundo a avaliação recebida.

\begin{tabular}{lccc}
\hline \multirow{2}{*}{ CONSAD } & \multicolumn{3}{c}{ Avaliação recebida } \\
& A & B & C \\
\hline Missões (RS) & 2 & 4 & 5 \\
Campos de Lages (SC) & 0 & 7 & 2 \\
Pitanga (PR) & 6 & 2 & 8 \\
Total & 8 & 13 & 15 \\
\hline
\end{tabular}

Fonte: Pesquisa de Campo (2004).

Nota: "A" projetos que receberam até 20 pontos na avaliação; "B" projetos que receberam entre 21e 25 pontos na avaliação; "C" projetos que receberam mais de 25 pontos na avaliação.

É importante mencionar que a nota atribuída reflete os atributos do projeto por ocasião do levantamento de informações e realização das entrevistas, cujos dados e documentos fornecidos serviram para subsidiar o processo de avaliação. Logo após encerrar-se esta etapa tomamos conhecimento de que algumas destas iniciativas foram reformuladas, como algumas situações em que novos municípios passaram a integrar um determinado projeto intermunicipal, visando fortalecer seu alcance e abrangência.

Em alguns casos tais mudanças foram influenciadas pela própria realização dessa pesquisa, na medida em que seus gestores perceberam a necessidade de fortalecer pactos territoriais e alianças estratégicas em 
torno de objetivos comuns e convergência de interesses. Outro aspecto digno de nota aconteceu quando alguns gestores, especialmente ligados ao poder público municipal, reconheceram a impostergável tarefa de integrar movimentos sociais e organizações civis no arranjo institucional do respectivo projeto.

Conscientes de que o excesso de protagonismo da prefeitura e de organizações estatais pudesse resultar num aspecto negativo na avaliação de um determinado projeto, alguns dos responsáveis mostraram-se menos refratários à inclusão de novos atores sociais e de estabelecer um novo concerto das forças vivas e do pacto político construído em torno à idéia-guia. Entrementes, há também situações em que esta flexibilização cumpre apenas aspectos protocolares, incorporando representações ${ }^{5}$ institucionais cujo ingresso visa tão somente conferir traços de legitimidade a um processo cuja dinâmica é absolutamente conservadora do ponto de vista da tomada de decisões, da definição das prioridades e da forma de implementar as ações.

\section{Os CONSADS frente aos desafios de construção da segurança alimentar}

É sabido que os CONSADs formam parte de uma nova estratégia no processo de intervenção estatal com vistas a estabelecer, dentre outros aspectos, uma nova institucionalidade voltada a aplacar a fome e a insegurança alimentar, fortalecendo o desenvolvimento local e a inclusão social. Busca-se assim fomentar o capital social e as sinergias do próprio território.

Contudo, muitos são os obstáculos a serem transpostos nessa caminhada. Alguns deles decorrem da própria dinâmica requerida para ope-

\footnotetext{
${ }^{5}$ Esse é outro tema que merece uma abordagem mais aprofundada enquanto objeto da reflexão acadêmica. Na recente proliferação de conselhos e consórcios em todo território nacional foi possível identificar a confusão reinante do ponto de vista dos princípios democráticos que orientam a dinâmica das relações entre os atores sociais envolvidos nestes mesmos processos. Indivíduos que participam destes conselhos falam, muitas das vezes, em nome próprio e não, como dever-se-ia esperar, em nome da instituição que representam. Como resultado, inúmeros são os casos em que este distanciamento é tão grande que compromete a articulação em torno dos próprios objetivos pelos quais ditos conselhos foram concebidos.
} 
rar as mudanças do ponto de vista da articulação com outras políticas públicas, do concerto das forças políticas, das desigualdades regionais, das restrições orçamentárias etc.

Impossível seria reproduzir estes desafios no espaço que aqui dispomos, não obstante ser esta uma tarefa não menos meritória e oportuna enquanto exercício de reflexão com vistas ao aperfeiçoamento da atuação estatal. O objetivo a que nos propomos, no espaço que segue, é o de resumidamente elencar e discutir algumas destas questões à luz da experiência recente do TCP FAO/BRA/2905 no âmbito dos recém-instalados CONSADs do Sul do Brasil.

Não temos a mínima pretensão de esgotar o assunto, nem mesmo realizar um balanço sobre os avanços e retrocessos a eles associados, desde que ocorreu sua efetiva implantação. Parte-se aqui da premissa de que é fundamental refletir sobre os limites e possibilidades dos CONSADs com base, não em meras discussões filosóficas, mas a partir do que se nos apresenta a realidade concreta.

A caminhada pelos rincões da geografia do Brasil meridional trouxe consigo elementos que buscamos tirar do limbo como um dos objetivos desse artigo, que, em essência, postula iluminar dito debate. Para tanto, lançamos mão do recurso ao exame de algumas das contradições mais relevantes constatadas ao longo dessa pesquisa. Algumas delas aludem a problemas de concepção ou de desenho institucional. Outras, destarte, tocam em aspectos pragmáticos e pontuais.

\section{O recorte territorial do CONSAD: consolidando a identidade regional?}

No marco conceitual que orientou a criação dos primeiros CONSADs aparecem associadas duas noções fundamentais: uma delas é a idéia de consórcio, a outra, de desenvolvimento local. O consórcio, segundo definem alguns juristas, seria um modelo de organização política dominante no futuro, significando um "... acordo de vontades entre duas ou mais pessoas jurídicas públicas da mesma natureza e mesmo nível de governo ou entre entidades da administração indireta para a consecução de objetivos comuns" (MOREIRA NETO, 2001, p.288).

Mas ainda que exista um arcabouço jurídico-institucional que dis- 
põe sobre a criação e o funcionamento desta entidade, não resta dúvida de que sua dinâmica de atuação traduz algumas dificuldades. A primeira delas reside no fato de não possuir personalidade jurídica do ponto de vista do direito administrativo, requerendo, para atingir as metas de seus consorciados, a criação de uma outra entidade civil ou comercial.

Porém, não são poucos os problemas associados a esta idéia. Em primeiro lugar, está a questão da representação e do poder político das chamadas "forças vivas" da sociedade vis a vis com as distintas esferas estatais (união, estado e município). Em segundo lugar, há que pensar nos limites impostos pela própria forma de organização. Em que município deve situar-se a sede do CONSAD, perguntavam-se prefeitos e grupos sociais organizados?

Se com vistas à obtenção de recursos o processo requer assinatura de convênios com as prefeituras municipais, para que serve, enfim, o CONSAD? Se juridicamente ele se assenta na idéia de um "acordo de programa” como forma de concretização de parcerias, em que circunstâncias ele deixaria de existir se, por ventura, as metas não forem cumpridas?

Outra questão que nos parece absolutamente pertinente a respeito dos CONSADs prende-se ao tema do recorte territorial em termos dos municípios que dele fazem parte. Em alguns casos pudemos constatar que seu desenho identifica-se razoavelmente com o conceito de microrregiões homogêneas adotado pelo IBGE. Em outros casos, tal como ocorre no CONSAD Missões, pode abarcar localidades integrantes de até três microrregiões diferentes.

Como informa Franca (2003, p.21), o "critério básico que norteará o desenho territorial de um CONSAD é o da identidade microrregional", cujo número de municípios esteja situado entre 5 a 15 localidades. Ainda que essa diretriz, segundo a mesma fonte, deva ser aplicada de forma flexível, não resta dúvida de que surgem problemas na medida que em muitos casos outros elementos foram levados em conta na opção por um determinado recorte territorial.

Algumas associações regionais ou de municípios vizinhos, criadas para cumprir objetivos distintos, converteram-se - da noite para o dia - em CONSADs, sem que ao menos fosse discutido se este desenho objetivamente atende aos novos compromissos de aplacar a fome e a insegurança alimentar. O resultado pode ser visto quando examinamos 
situações diametralmente opostas do ponto de vista dos municípios que dele fazem parte em termos dos indicadores de pobreza, indigência, acesso a serviços sociais básicos etc. Como é possível construir um pacto territorial e um discurso unificado no plano do próprio CONSAD quando a realidade mostra-se tão contraditória em termos estruturais?

Em termos pragmáticos indagamos: é possível o CONSAD estabelecer prioridades do ponto de vista dos projetos a serem apoiados quando os municípios que o compõem são tão discrepantes entre si? No caso gaúcho esse problema foi constatado no desenho do CONSAD Missões que abriga em seu interior municípios com um alto IDH e outros que figuram entre as localidades pior classificadas do ponto de vista da renda, alfabetização e condições sociais.

Sobre a questão do desenvolvimento local há uma outra ambigüidade básica a ser superada no marco conceitual do CONSAD. Ela surge na medida em que, de um lado, há a intransigente defesa das virtudes da articulação microrregional enquanto forma de viabilizar alianças, de estabelecer ações sinérgicas e de avançar rumo à construção de pactos territoriais entre atores sociais (públicos e privados) de municípios contíguos e/ou vizinhos.

Por outro lado, parte-se do princípio de existência de uma "imbricação natural dos CONSAD (sic) com os pressupostos do Desenvolvimento Local" (FRANCA, 2003, p.11). Ainda que local e região possam ser entendidas como estágios de uma mesma escala territorial, não resta dúvida de que a ambigüidade permanece evidenciada.

De um modo mais objetivo, poder-se-ia indagar: qual o tamanho do local num processo de desenvolvimento que, em tese, aspira incidir sobre uma microrregião? Qual é verdadeiramente a unidade de análise e referência do CONSAD e o papel correspondente ao local na consolidação de políticas de segurança alimentar em nível regional?

O CONSAD pode e deve desempenhar um papel transcendental no combate à fome e à insegurança alimentar, do mesmo modo que vem sendo utilizado como recurso para viabilizar ações em outras áreas, tais como recuperação e proteção ambiental, recursos hídricos e saneamento, tratamento de resíduos sólidos, cultura, saúde, produção agropecuária, abastecimento, obras públicas etc.

Mas para isso é crucial refletir, segundo nosso entendimento, sobre 
tais questões, antes de converter o tema numa panacéia capaz de solucionar todos os problemas e dificuldades interpostas na caminhada em prol da construção da segurança alimentar. A construção do CONSAD não pode ser vista como apanágio das mudanças que se quer estabelecer, desconsiderando a imperiosa necessidade de empreender transformações estruturais que cada contexto está a exigir.

\section{A síndrome "chapa branca"}

A chamada constituição cidadã consagrou, desde 1988, inúmeras mudanças no ordenamento político e institucional do Brasil. Entre elas figura a transferência de competências do Estado, corroborando, em última análise, o princípio da municipalização das políticas públicas no campo da saúde, educação segurança pública etc. Desde então proliferam no país conselhos municipais encarregados de deliberar sobre inúmeras questões, que vão da alocação de recursos aos critérios definidores do público alvo de políticas públicas.

Se por um lado, houve um efetivo "empoderamento" da sociedade civil na condução dos processos sócio-políticos, incontáveis são os exemplos do que se convencionou chamar de "prefeiturização" enquanto tendência ao protagonismo excessivo dos poderes públicos.

Ainda que reconheçamos as dificuldades de implementação dos CONSADs e os problemas associados à sua peculiar dinâmica de funcionamento, há que reconhecer que esse "acordo de vontades entre duas ou mais pessoas jurídicas públicas da mesma natureza (...) ou entre entidades da administração indireta" (MOREIRA NETO, 2001, p.288) pode traduzir-se na incorporação de elementos novos e benéficos para o cotidiano das comunidades.

Isso ocorreria desde que houvesse elementos que conferissem legitimidade em sua composição e objetivos, bem como a existência de mecanismos efetivos de controle social e de participação democrática do ponto de vista dos atores sociais envolvidos.

O que aqui provocativamente denominamos "síndrome chapa branca” nos foi sugerida no discurso ${ }^{6}$ de um dos entrevistados, vinculado

${ }^{6} \mathrm{O}$ elevado número de carros oficiais no local das assembléias coincide com a inexistência de meios que assegurem o deslocamento e participação de representantes de 
a um movimento social, que criticava a posição hegemônica dos prefeitos na condução do processo de implantação de um dos CONSADs estudados. Ainda que dito empenho seja meritório, no afã de que estes vejam aprovados seus projetos, muitas lideranças influenciam a escolha dos representantes locais na estrutura do CONSAD, condicionando esta eleição segundo seus próprios interesses, desvirtuando, em última análise, o princípio do equilíbrio das forças políticas.

No marco metodológico do TCP FAO/BRA/2905 estabelecemos, como aludido anteriormente, sete critérios de avaliação dos projetos intermunicipais de desenvolvimento. Três deles (pacto político, viabilidade institucional e sustentabilidade financeira) têm a ver diretamente com o problema aqui levantado. Alguns de nossos interlocutores conscientizaram-se da necessidade de corrigir suas próprias posturas.

Indiscutivelmente, as assembléias de devolução da pesquisa serviram para colocar a questão em tela. Bons projetos foram assim considerados, entre outros fatores, por haver um concerto de forças políticas mais equilibrado, estabelecendo alianças em torno a programas factíveis e consistentes, onde os papéis estão distribuídos de modo satisfatório.

No nosso entendimento, apesar das incontáveis limitações, a experiência do TCP FAO/BRA/2905 significou, indubitavelmente, um marco referencial para a elaboração de projetos relacionados ou não com o tema da segurança alimentar, tanto para os poderes públicos quanto para organizações civis.

\section{Desenvolvimento rural ou agrícola? O viés agrário das propostas...}

É nítida e indiscutível a presença de traços rurais nos municípios que integram os CONSADs recém-instalados no país e, fundamentalmente, na Região Sul do Brasil, entendida aqui do ponto de vista do pre-

movimentos sociais e organizações da sociedade civil. A estas pessoas restam duas alternativas para fazerem-se presentes nas reuniões do CONSAD: convencer o sindicato ou o órgão a que se encontra vinculado a arcar com as despesas ou, literalmente, "pegar uma carona" no carro da prefeitura, com todos os constrangimentos que esse ato possa traduzir. Há uma orientação geral de que as prefeituras municipais contribuam com $0,5 \%$ do Fundo de Participação dos municípios para manter a estrutura e os gastos do CONSAD. Todavia, até o presente momento, desconhecemos situações em que esta medida foi concretamente posta em prática. 
domínio de uma baixa densidade demográfica. Valendo-se desse mesmo critério, $80 \%$ do espaço europeu é considerado "rural", tal como conclui um importante documento produzido no começo dos anos 1990 pela então CEE.?

Por que torna-se tão importante fazer esse tipo de ponderação? A questão é que, como indicam outros estudos (ABRAMOVAY, 2003, p.98), desenvolvimento agrícola não implica necessariamente desenvolvimento rural. A bem da verdade ambos conceitos podem inclusive supor caminhos opostos. Esta antinomia aparece claramente evidenciada quando refletimos sobre a trajetória brasileira e latino-americana recente.

No padrão "revolução verde", que se consolidou a partir da segunda metade dos anos 60, a rápida incorporação de insumos modernos levou, entre outras coisas, ao aprofundamento do processo de esvaziamento do campo, à desaparição de muitas unidades familiares de produção, bem como a outros fenômenos igualmente importantes ${ }^{8}$. Não é necessário insistir muito para ilustrar quão opostos podem ser os caminhos que conduzem, de um lado, à ampliação das oportunidades e condições de vida de um setor da população nacional, e, de outro, à desenfreada carreira por aumentar a produção e a produtividade das lavouras e criações.

Essa pequena digressão faz-se necessária para refletir sobre alguns elementos em relação aos quais nos interessa refletir. Os dados que anteriormente mostramos dão conta de que $42 \%$ dos projetos locais investigados têm como idéia-guia dominante a organização de agricultores, apoio a cadeias produtivas e aos processos de comercialização. Do mesmo modo 48,9\% deles concebem o agricultor familiar como categoria sócio-política privilegiada nas ações previstas.

O perfil dos projetos intermunicipais de desenvolvimento não difere desse quadro, tendo em vista que em $41,7 \%$ dos projetos a idéia-guia dominante é o apoio às cadeias produtivas e a processos de comercialização, ao passo que em quase $53 \%$ dos casos é o agricultor familiar o ator social privilegiado das propostas.

Não se trata aqui de considerar a ênfase agrarista dos projetos como

${ }^{7}$ Referimo-nos aqui a "O Futuro do Mundo Rural”, elaborado pela Comissão Européia. Sobre essa questão ver a propósito Sacco dos Anjos e Caldas (2004).

${ }^{8}$ Referimo-nos ao tema da masculinização e envelhecimento da população rural aludido anteriormente. 
algo necessariamente negativo. O problema está em desconhecer a imperiosa necessidade de articulação entre o fortalecimento de uma atividade produtiva com a geração de oportunidades, de trabalho e renda, sejam elas de natureza agrária ou não-agrária, do mesmo modo que um bom programa de segurança alimentar não pode ser assim considerado se limitado à mera distribuição de gêneros alimentícios.

No afã de ilustrar essa questão evocamos a experiência da Prefeitura de Giruá (RS) com seu projeto de merenda escolar ecológica. Examinemos os aspectos que podem reavivar esse debate. Não é de hoje que se detectam inúmeros problemas associados à questão da merenda escolar. A questão recai, entre outros aspectos, na própria qualidade nutricional dos artigos consumidos na escola, no custo de aquisição e distribuição dos produtos e, paradoxalmente, por incutir hábitos alimentares absolutamente discutíveis sob a ótica da saúde e nutrição. Muitos pais e familiares estavam conscientes da necessidade de enfrentar esse problema. Mas a questão não diz respeito apenas aos apelos publicitários que incitam ao consumo de refrigerantes, salgadinhos e guloseimas, mas no fato de que ditos artigos estão comumente postos à disposição das crianças nos bares e cantinas escolares.

Por outro lado, havia o reconhecimento, por parte das autoridades locais, de que um dos problemas centrais que enfrentam os agricultores familiares é justamente assegurar um mercado consumidor para produtos perecíveis, como no caso dos hortigranjeiros, assim como para os artigos da chamada "indústria doméstica rural” (pães, bolachas, geléias, sucos), tendo em vista a inexistência de espaços e estruturas compatíveis com suas necessidades de escoamento da produção.

A prefeitura iniciou este processo inspirada na experiência de Pelotas, RS, onde esse sistema já se encontrava consolidado e em funcionamento há alguns anos. Além do treinamento das merendeiras e das reuniões com os pais, a equipe de trabalho, integrada por uma nutricionista, montou um plano que apontava para a necessidade de trabalhar a reeducação alimentar. Inúmeros obstáculos surgiram na implementação do projeto. Figuram em destaque os embaraços burocráticos para operar as compras da agricultura familiar, o convencimento dos produtores na oferta de artigos padronizados e de qualidade, a organização dos grupos e a logística do fornecimento às escolas e, de maneira ainda 
mais destacada, a sensibilização das merendeiras da escola em relação ao papel que a elas cabia na condução desta idéia e do processo posto em marcha pela prefeitura.

Paralelamente, a prefeitura buscou incutir, entre as professoras e diretores de escola, a necessidade de que este tema fosse trabalhado em sala de aula como matéria curricular. Todas as seis escolas municipais foram integradas ao projeto. Por ocasião da realização da pesquisa nada menos que $20 \%$ dos alimentos consumidos na escola eram ecologicamente produzidos por agricultores familiares e assentados em projetos de reforma agrária do próprio município de Giruá.

Ainda que limitada, esta experiência pode e deve ser replicada em outras latitudes, cujo perfil é meritório justamente por fugir do esquema clássico e rígido de fomento a uma determinada cultura ou atividade. $\mathrm{O}$ que está em jogo é uma concepção que alia em torno de si objetivos inegavelmente impactantes sob a perspectiva do desenvolvimento regional e humano. De novo insistimos no fato de que não se trata de desconsiderar a importância e o potencial da agricultura enquanto instrumento de redução das desigualdades no contexto de regiões tipicamente rurais. O desafio está em conectar esses objetivos com outras questões de importância transcendental e de objetivamente encher de significado o conceito de segurança alimentar. Uma conexão que integre produção e consumo, educação e cidadania, inclusão social e solidariedade.

\section{Pobres não são necessariamente famintos...}

A cruzada em torno ao combate à insegurança alimentar esbarra também em outros equívocos interpretativos. Um deles parece ser o de confundir pobres com famintos. Esse erro decorre da insistência em ilações surgidas do exame de dados estatísticos, tais como os índices de pobreza e indigência que podem ser úteis, no limite, para auxiliar na identificação de regiões prioritárias para intervir na realidade e aplacar desigualdades. Em verdade, essa tendência é constatada, não apenas no debate acadêmico, mas fundamentalmente no discurso e na práxis dos gestores públicos e de organizações não-governamentais.

Para chegar aos dados que fundamentam tais conceitos o IBGE leva em conta a renda domiciliar e pessoal. Porém, sob a ótica dos domicí- 
lios rurais, o grande problema é justamente subestimar a produção de autoconsumo e as estratégias de auto-provisão de que lançam mão as famílias para viabilizar um nível de consumo socialmente aceitável. Nesta dimensão, a título de referência, podemos mencionar o escambo que praticam remanescentes de quilombos, a troca de dias entre vizinhos, os mutirões, entre outros mecanismos que não são levados em conta nas análises usuais que invariavelmente priorizam fluxos monetários, receitas e custos de produção.

Não se trata apenas de uma simples provocação ao debate acadêmico, mas de reconhecer o valor intrínseco destas práticas que devem ser levadas em conta na formulação e no desenho das políticas públicas. Um bom programa de segurança alimentar poderia justamente ser feito a partir do resgate sobre a importância destas práticas onde houvessem sido esquecidas ou negligenciadas. Poder-se-ia aumentar a disponibilidade protéica na dieta de uma família via distribuição de ovos e cestas básicas. Do mesmo modo chegaríamos aos mesmos resultados comprometendo seus membros em cuidar de poedeiras doadas e de construir uma horta atrás da casa em que as pessoas vivem.

A questão não é somente minimizar a dependência de fontes externas de renda, mas de combater a cultura política do assistencialismo. Nesse sentido parece óbvio o fato de que pobres não são necessariamente famintos.

\section{Aproximando discursos e ações ou batendo cabeças?}

Há um outro aspecto que nos parece igualmente relevante pensar, à luz das impressões colhidas no trabalho desenvolvido junto aos CONSADs da região Sul do Brasil. Ele tem a ver, de um lado, com a atuação dos atores sociais diretamente implicados na implantação dos CONSADs e, de outro, com as agências do Estado que direta ou indiretamente envolveram-se com oferecer alternativas de combate à fome, insegurança alimentar e desenvolvimento local.

No primeiro caso, a pesquisa realizada trouxe à tona situações em que há um nítido processo de esgotamento nas propostas na medida em que muitas ações poderiam ser articuladas entre os próprios municípios, aumentando sua eficiência do ponto de vista dos resultados e da inci- 
dência no espaço regional. A transferência direta de renda tem de estar articulada com outros instrumentos locais de intervenção e não da forma compartimentada como em boa medida vem acontecendo. Do mesmo modo, há que aprofundar os mecanismos de controle social. No intuito de apressar a implantação do bolsa-família, houve, como é sabido, a desativação dos comitês gestores do Fome Zero, trazendo graves prejuízos à credibilidade deste programa. No segundo caso, nossa atenção está orientada à imperiosa tarefa de aglutinar forças, evitando sombreamentos em suas respectivas estratégias de atuação. Ainda que preliminares, alguns passos já estão sendo dados na aproximação que fazem os ministérios do Desenvolvimento Social e Desenvolvimento Agrário. Ainda assim, há muito que fazer no estabelecimento de uma agenda mínima de trabalho, a qual, forçosamente, deveria incluir outras pastas do Executivo federal. O CONSAD necessariamente representa um importante espaço de interlocução entre os atores sociais envolvidos, podendo assumir um nível de protagonismo ainda maior em prol da consolidação de metas factíveis.

Não apenas agricultores familiares consolidados, mas principalmente assentados da reforma agrária deveriam estar inseridos no centro do debate sobre a formulação de políticas de segurança alimentar regional. É nesse sentido que medidas estruturais devem estar integradas com iniciativas de curto e médio prazo. Compor essa agenda mínima é absolutamente crucial para ampliar o foco de atuação das políticas, sem prejuízo das competências do aparato estatal.

\section{Considerações finais}

Seria absolutamente prematuro realizar qualquer balanço a respeito dos resultados alcançados após a recente implantação dos primeiros três CONSADs nos estados do Sul do Brasil. Não foi essa a tarefa desenvolvida pela equipe de pesquisadores da Universidade Federal de Pelotas. A missão que se buscou desenvolver é a geração de uma metodologia de avaliação de projetos de desenvolvimento, em parceria com outras equipes lideradas pelas Universidades Federais de Lavras e Uberlândia. Simultaneamente, havia que identificar, caracterizar e classificar estas experiências de acordo com os objetivos do Programa Fome Zero no âmbito dos CONSADs de Missões, Campos de Lages e Pitanga. 
O texto aqui apresentado representa a culminação de um trabalho realizado durante os meses de janeiro a agosto de 2004 e que trouxe, como resultado imediato, um amplo diagnóstico e avaliação sobre um total de 137 projetos de desenvolvimento, sendo que 88 deles representam iniciativas locais, ao passo que 36 formam parte do que se denomina projetos intermunicipais de desenvolvimento. Os 13 restantes foram enquadrados como PIDs em fase de estruturação.

De um modo absolutamente pragmático, o trabalho executado identificou alguns entraves e gargalos tanto no processo de implantação dos CONSADs quanto na dinâmica que acompanha as ações empreendidas. Nos parágrafos precedentes deixamos registradas algumas das medidas que podem ser tomadas para avançar e tornar ainda mais efetivo o papel dos CONSADs enquanto espaço sócio-político privilegiado para discutir e implementar ações efetivas de combate à fome e à insegurança alimentar. Não há a mínima pretensão de esgotar o tema ou de oferecer soluções mágicas frente ao problema da fome, que, como é sabido, trata-se de uma das grandes mazelas nacionais.

Na verdadeira cruzada por reduzir as desigualdades nacionais, e resgatar a enorme dívida social, não cabem atalhos. Os olhos do planeta estão postos sobre o Brasil que, ao eleger a meta de afrontar esse problema, impõe uma mudança de rumos na consciência mundial, influenciando muitos países e organizações mundiais no sentido de estabelecer programas inspirados nos mesmos objetivos.

\section{Referências bibliográficas}

ABRAMOVAY, R. O capital social dos territórios: repensando o desenvolvimento rural, in: ABRAMOVAY, R. O Futuro das regiões rurais, Porto Alegre: UFRGS, 2003, p.83-100. 149p.

BRASIL. Instituto Brasileiro de Geografia e Estatística, IBGE, Censo Demográfico 2000. Rio de Janeiro, Brasil, 2000.

CANDIDO, A. Os parceiros do Rio Bonito. São Paulo: Livraria Duas Cidades, 1987. $7^{\mathrm{a}}$ ed.

CAMARANO, A. e ABRAMOVAY, R. Êxodo Rural, Envelhecimento e 
Masculinização no Brasil: Panorama dos últimos cinqüenta anos. In: XXI ENCONTRO ANUAL DA ANPOCS, 1997, 20 p. (mimeo)

COLEMAN, J. S. Foundations of social theory. Cambridge, London: The Belknap Press of Harvard University Press, 1990.

COMISIÓN EUROPEA. El futuro del mundo rural. Madri: MAPA, 1992. 149 p. (Documento 7957/88). Comunicación de la Comisión al Consejo y al Parlamento.

FRANCA, L. P. CONSAD - Formação de Consórcios de Segurança Alimentar e Desenvolvimento Local, Rio de Janeiro: IBAM/DES/NEL, 2003. $164 \mathrm{p}$.

KAYSER, B.; BRUN, A.; CAVAILLÈS, J.; LACOMBE, P. Pour une ruralité choisie. Paris: Datar Éditions de l’Aube, 1994.

MOREIRA NETO, D. Mutações do Direito Administrativo, $2^{\mathrm{a}}$ ed., Rio de Janeiro: Renovar, 2001.

PUTNAM, R. D Comunidade e democracia: A experiência da Itália moderna. Rio de Janeiro: Fundação Getúlio Vargas, 1996.

SACCO DOS ANJOS, F. Agricultura Familiar, Pluriatividade e Desenvolvimento Rural no Sul do Brasil. Pelotas: EGUFPEL, 2003, 374p.

SACCO DOS ANJOS, F. e CALDAS, N.V. Pluriatividade e Ruralidade: Falsas Premissas e Falsos Dilemas, in: CAMPANHOLA, C. e GRAZIANO DA SILVA, J. (eds) O Novo Rural Brasileiro: Novas ruralidades e urbanização, v. 7, Brasília: Embrapa, 2004, p.71-105. 216 p.

SACCO DOS ANJOS, F. e CALDAS, N.V. Cambios demográficos en el Brasil meridional: la masculinización, el envejecimiento y la desagrarización de la población rural, in: Perspectivas Sociales/Social Perspectives, v. 5, nº 2, México: Universidad Autónoma de Nuevo León, p. 71-111.

Recebido em julho de 2006 e revisto em outubro de 2006. 